\title{
EFEKTIFITAS PROGRESSIVE MUSCLE RELAXATION TERHADAP KECEMASAN PADA PASIEN KANKER PAYUDARA YANG MENJALANI KEMOTERAPI
}

\author{
Ricky Z1, Rini Rachmawaty ${ }^{2}$, Yuliana Syam² \\ 1,2,3 Universitas Hasanudin, Program Studi Magister Ilmu Keperawatan, Makassar \\ Diterima : 27 Agustus 2018, Disetujui : 10 September 2018 \\ e-mail : rickyz.rz22@gmail.com
}

\begin{abstract}
Backgound: Progressive Muscle Relaxation (PMR) exercise therapy is a focused therapy to maintain deep relaxation conditions. Empirical evidence has supported the use of Progressive Muscle Relaxation (PMR) in reducing headaches, insomnia, hypertension, and additional treatment in cancer patients and management of chronic pain. This article analyzes the effectiveness of Progressive Muscle Relaxation (PMR) in reducing anxiety and by reviewing the results of the current study. Method: This study explores quantitative evidence published in electronic database, such as Pubmed, Google Scholar, and ProQuest. By using electronic publications, we have identified 193 potential and relevant articles of interest while fifteen studies have been included in the final analysis. Results: the study shows that a significant improvement occurred in a post-intervention in reducing anxiety for participants receiving PMR compared to all control groups. Conclusion: The result indicates that PMR is a particularly useful supplementary treatment to reduce anxiety levels of cancer patients undergoing chemotherapy and nurses must be trained to perform Progressive muscle relaxation.
\end{abstract}

Keywords: Anxiety, Progressive Muscle Relaxation, Breast Cancer.

\section{PENDAHULUAN}

Kanker, sebagai salah satu masalah kesehatan yang mengalami peningkatan sangat cepat dan menjadi penyebab kedua kematian di dunia (Shahriari, Dehghan, Pahlavanzadeh, \& Hazini, 2017). Hal ini dapat dilihat dari semakin banyaknya laporan bahwa penyakit kanker cenderung menjadi salah satu penyebab utama kematian diusia produktif (Lauche et al., 2013), dan salah satu penyakit kanker yang sering terjadi adalah kanker payudara.

Berdasarkan data GLOBOCAN, International Agency for Research on Cancer (IARC), diketahui bahwa diseluruh dunia pada tahun 2012 terdapat
14.067.894 kasus baru kanker dan 8.201.575 kematian akibat kanker. Khusus untuk penyakit kanker payudara $43,1 \%$ kasus baru dan 12,9\% angka kematian akibat kanker payudara. Di Indonesia sebanyak 61.682 kasus dengan diagnosis kanker payudara, dan untuk Propinsi Sulawesi Selatan sebanyak 2.975 kasus (Pusdatin, 2016). Data yang diperoleh dari RSUP DR Wahidin Sudirohusodo Makassar jumlah penderita kanker payudara yang menjalani kemoterapi pada tahun 2017 sebanyak 814 orang, sedangkan pada periode januari s/d april 2018 sebanyak 375 orang (Rekam Medik, 2018). 
Kemoterapi merupakan salah satu terapi medis yang digunakan dalam pengobatan kanker, terutama terhadap kanker sistemik dan kanker dengan metastasis klinis ataupun subklinis

Akan tetapi, kemoterapi dapat mengakibatkan efek samping seperti alopesia, mual muntah, gangguan saluran cerna, gangguan keseimbangan cairan elektrolit dan stomatitis (Herizchi, Asvadi, Piri, \& Golchin, 2012). Akibat efek samping yang sering terjadi pada saat kemoterapi, menyebabkan pasien menjadi cemas sehingga mereka memilih untuk menghentikan siklus terapi yang dapat mempengaruhi kualitas hidup di masa datang (Syarif \& Putra, 2014).

Untuk pasien yang menjalani kemoterapi, dukungan psikologis sangat diperlukan untuk membantu pasien mengatasi status penyakitnya, mengurangi kecemasan, rasa sakit, dan memperkuat status psikologis mereka (Lee, Bhattacharya, Sohn, \& Verres, 2012). Selain itu, pasien juga dapat diberikan terapi perilaku seperti terapi relaksasi yang merupakan suatu metode terapi melalui prosedur relaksasi otot, agar pasien secara sadar mengendalikan aktivitas fisik dan psikis, sehingga dapat menstabilkan emosi dan mengatasi gejala penyakitnya terutama kecemasan akibat kemoterapi. Salah satu terapi yang dapat digunakan untuk mengurangi kecemasan adalah Progressive Muscle Relaxation (PMR) (Syarif \& Putra, 2014).

Banyak pasien kanker
menggunakan berbagai teknik untuk meningkatkan kesejahteraan fisik dan mental mereka, termasuk terapi relaksasi khususnya, Progressive Muscle Relaxation (PMR). Khasiat PMR ditemukan hampir setara dengan menerima $0,5 \quad \mathrm{mg}$ alprazolam triazolobenzodiazepine tiga kali sehari (Lee et al., 2012).

\section{METODE PENELITIAN}

Tinjauan literatur dilakukan melalui penelusuran hasil-hasil publikasi ilmiah pada rentang tahun 2010-2017 menggunakan database pubmed, google scholar, proquest. Pada database pubmed dengan memasukkan keyword 1 "Progressive Muscle Relaxation" ditemukan 2.023 artikel. Keyword 2 "anxiety" ditemukan 203.438 artikel. Keyword 3 "chemotherapy" ditemukan 3.016.747 artikel. Keyword 4 "breast cancer" ditemukan 3.625.821 artikel. Keyword 5 dilakukan penggabungan keyword 1, 2, 3 dan 4 yaitu " "Progressive Muscle Relaxation AND anxiety AND chemotherapy AND breast cancer" ditemukan 16 artikel. Setelah dilakukan pencarian artikel, selanjutnya dilakukan pembatasan jumlah artikel sesuai kriteria penelitian dengan langkah-langkah : LIMIT Clinical trial ditemukan 8 artikel. LIMIT Abstract ditemukan 8 artikel. LIMIT full text ditemukan 7 artikel. LIMIT to date (2010-2017) ditemukan 6 artikel. LIMIT of humans ditemukan 6 artikel.

Pada database google scholar dengan memasukkan keyword 1 "Progressive Muscle Relaxation" ditemukan 235.000 artikel. Keyword 2 "Progressive Muscle Relaxation AND anxiety" ditemukan 56.200 artikel. Keyword 3 "Progressive Muscle Relaxation AND chemotherapy" ditemukan 24.900 artikel. Keyword 4 "Progressive Muscle Relaxation AND cancer" ditemukan 56.700 artikel. Keyword 5 "Progressive Muscle Relaxation AND randomized controlled trials" ditemukan 44.900 artikel. Keyword 6 dilakukan penggabungan keyword 1, 2, 
3, 4 dan 5 yaitu "Progressive Muscle Relaxation" AND "Progressive Muscle Relaxation AND anxiety" AND "Progressive Muscle Relaxation AND chemotherapy" AND "Progressive Muscle Relaxation AND cancer" AND "Progressive Muscle Relaxation AND randomized controlled trials" ditemukan 2.220 artikel. Setelah dilakukan pencarian artikel, selanjutnya dilakukan pembatasan jumlah artikel LIMIT to date (after 2016) ditemukan 208 artikel. LIMIT relevansi ditemukan 187 artikel.

\section{PEMBAHASAN}

\section{Kanker payudara}

Kanker payudara merupakan gangguan dalam pertumbuhan sel normal payudara dimana sel abnormal timbul dari sel-sel normal, berkembang biak dan menginfiltrasi jaringan limfe dan pembuluh darah (Nurarif, Amin \& Kusuma, 2015). Kanker payudara merupakan penyakit keganasan yang paling banyak menyerang wanita dan merupakan penyebab kematian terbesar kedua setelah penyakit kanker paru (Black \& Hawks, 2014). Dengan melihat hal tersebut, dapat dikatakan bahwa, penyakit kanker payudara merupakan penyakit yang memiliki prevalensi kejadian yang cukup tinggi.

Berdasarkan data GLOBOCAN, International Agency for Research on Cancer (IARC), diketahui bahwa diseluruh dunia pada tahun 2012 terdapat 14.067.894 kasus baru kanker dan 8.201.575 kematian akibat kanker. Khusus untuk penyakit kanker payudara 43,1\% kasus baru dan 12,9\% angka kematian akibat kanker payudara. Di Indonesia sebanyak 61.682 kasus dengan diagnosis kanker payudara, dan untuk Propinsi Sulawesi Selatan sebanyak 2.975 kasus
(Pusdatin, 2016). Data yang diperoleh dari RSUP DR Wahidin Sudirohusodo Makassar jumlah penderita kanker payudara yang menjalani kemoterapi pada tahun 2017 sebanyak 814 orang, sedangkan pada periode januari s/d april 2018 sebanyak 375 orang (Rekam Medik, 2018).

\section{Penatalaksanaan Kemoterapi}

Kemoterapi merupakan salah satu terapi medis yang digunakan dalam pengobatan kanker, terutama terhadap kanker sistemik dan kanker dengan metastasis klinis ataupun subklinis. Pada kanker stadium lanjut, kemoterapi merupakan satu-satunya metode pilihan yang sangat efektif (Syarif \& Putra, 2014). Akan tetapi, kemoterapi dapat mengakibatkan efek samping seperti alopesia, mual muntah, gangguan saluran cerna, gangguan keseimbangan cairan elektrolit dan stomatitis (Herizchi, Asvadi, Piri, \& Golchin, 2012). Akibat efek samping yang sering terjadi pada saat kemoterapi, menyebabkan pasien menjadi cemas sehingga mereka memilih untuk menghentikan siklus terapi yang dapat mempengaruhi kualitas hidup di masa datang (Syarif \& Putra, 2014). Menurut (Lazarus dan Folkman 1984), kecemasan dapat terjadi akibat dari diferensiasi antara orang dan lingkungannya. Ketika rasa ancaman tidak seimbang dengan rasa dukungan serta kemampuan untuk menghadapi situasi yang sulit, maka akan akan terjadi reaksi psikologis seperti cemas sehingga akan menghambat kesehatan psikologis pasien (Tsitsi, Charalambous, \& Papastavrou, 2017). Kecemasan yang dialami pasien kanker payudara dapat timbul akibat perasaan ketidakpastian tentang penyakit, pengobatan, dan prognosa (Syarif \& Putra, 2014). 


\section{Kecemasan}

Menurut (Montaño, D. E., \& Kasprzyk, 2008), kecemasan adalah suatu manifestasi dari berbagai proses emosi yang bercampur baur, yang terjadi ketika orang sedang mengalami tekanan perasaan dan pertentangan bathin atau konflik. Stimulus terhadap stress/cemas melibatkan pengaktifan sistem saraf simpatis dan pengeluaran berbagai macam hormon dan peptida, termasuk sumbu hypothalamic-pituitary-adrenal (HPA), sistem opioid endogen, arginin vasopresin, dan oksitosin (Corwin, 2008). Reaksi saraf simpatis terjadi karena adanya stimulus stress/cemas merangsang HPA. Aktivasi sumbu HPA bermula dengan pengeluaran corticotropin- releasing hormone ( $\mathrm{CRH})$ dari inti paraventrikular hipotalamus menuju ke aliran darah portal hipotalamus-hipofisis, yang pada tugasnya merangsang pengeluaran adrenocorticotropic hormone (ACTH) dari hipofisis anterior, sama halnya seperti arginine-vassopressin (AVP) dari kelenjar pituitari posteriorior (Lazenby, 2011).

Kecemasan yang dirasakan pasien kanker dapat muncul akibat tidak adanya kepastian penyembuhan tentang penyakit, pengobatan, dan prognosisnya. Kecemasan yang tidak diatasi dengan baik dapat menimbulkan rangsangan pada korteks serebri yang kemudian dapat menstimulasi pusat muntah, sehingga besar kemungkinan untuk terjadinya peningkatan keluhan mual dan muntah akibat kemoterapi. Kecemasan juga dapat memperburuk keluhan mual dan muntah, dan mual dan muntah itu sendiri dapat menimbulkan kecemasan. Sehingga merupakan siklus lingkaran setan yang harus diputuskan melalui berbagai upaya (Syarif \& Putra, 2014).
Untuk pasien yang menjalani kemoterapi, dukungan psikologis sangat diperlukan untuk membantu pasien mengatasi status penyakitnya, mengurangi kecemasan, rasa sakit, dan memperkuat status psikologis -mereka (Lee, Bhattacharya, Sohn, \& Verres, 2012). Selain itu, pasien juga dapat diberikan terapi perilaku seperti terapi relaksasi yang merupakan suatu metode terapi melalui prosedur relaksasi otot, agar pasien secara sadar mengendalikan aktivitas fisik dan psikis, sehingga dapat menstabilkan emosi dan mengatasi gejala penyakitnya terutama kecemasan akibat kemoterapi. Salah satu terapi yang dapat digunakan untuk mengurangi kecemasan adalah Progressive Muscle Relaxation (PMR) (Syarif \& Putra, 2014).

\section{Progressive Muscle Relaxation}

Banyak pasien kanker menggunakan berbagai teknik untuk meningkatkan kesejahteraan fisik dan mental mereka, termasuk terapi relaksasi khususnya, Progressive Muscle Relaxation (PMR). Khasiat PMR ditemukan hampir setara dengan menerima $0,5 \quad \mathrm{mg}$ alprazolam triazolobenzodiazepine tiga kali sehari (Lee et al., 2012).

Terapi latihan Progressive Muscle Relaxation (PMR) merupakan terapi yang terfokus untuk mempertahankan kondisi relaksasi yang dalam. Terapi PMR melibatkan kontraksi dan relaksasi berbagai kelompok otot mulai dari kaki kearah atas atau dari kepala kearah bawah. Untuk meregangkan otot secara progresif, dimulai dengan menegangkan dan meregangkan kumpulan otot utama tubuh. Dengan cara ini, maka akan disadari dimana otot itu berada dan hal ini akan meningkatkan kesadaran terhadap respon 
otot tubuh terhadap stres atau ketegangan (Syarif \& Putra, 2014).

Pelatihan Progressive Muscle Relaxation (PMR) merupakan teknik yang terus menerus dan sistematis untuk mengatasi peregangan dan membuat otototot menjadi rileks (Zhou et al., 2014).

Saat dilakukan PMR, dua komponen gerakan utama yang terjadi didalam tubuh, yaitu menegangkan otot dan merelaksasikannya, tujuan dari gerakan PMR ini ada beberapa macam diantaranya: menurunkan nyeri, menurunkan tekanan darah, menurunkan kecemasan, dan stress (Conrad \& Roth, 2007). Hal ini terjadi dengan jalur neuromuscular afferent menginervasi formasi retikuler, yang kemudian memproyeksikan hypothalamus posterior. Pengurangan otot skeletal saat melakukan gerakan menyebabkan hilangnya nada ergotropik hypothalamus, berkurangnya muatan korteks hypothalamus, sehingga mendominasi system thropotropik melalui aktifitas timbal balik antara ergotropik dan trhopotropik, sehingga terjadi promosi istirahat dan perbaikan dalam tubuh, yang merupakan respon penurunan kecemasan dan stress (Conrad \& Roth, 2007).

Hal ini terjadi dengan jalur neuromuscular afferent menginervasi formasi retikuler, yang kemudian memproyeksikan hypothalamus posterior. Pengurangan otot skeletal saat melakukan gerakan menyebabkan hilangnya nada ergotropik hypothalamus, berkurangnya muatan korteks hypothalamus, sehingga mendominasi system thropotropik melalui aktifitas timbal balik antara ergotropik dan trhopotropik, sehingga terjadi promosi istirahat dan perbaikan dalam tubuh, yang merupakan respon penurunan kecemasan dan stress (Conrad \& Roth, 2007).
Hasil penelitian yang dilakukan oleh (Tsitsi et al., 2017), bertujuan untuk menilai efek Progressive Muscle Relaxation (PMR) dan Guide Imagery (GI), dalam mengurangi tingkat kecemasan di kalangan orang tua dengan anak yang didiagnosis dengan semua jenis keganasan yang menerima pengobatan aktif di Unit Onkologi Anak di Republik Siprus. Jumlah sampel sebanyak 54 orang tua dari anak-anak yang dirawat di rumah sakit dengan keganasan yang dipilih secara acak. Pada hasil penelitian menunjukkan ada perbedaan kecemasan secara signifikan antara kelompok kontrol dan kelompok intervensi (2,63 vs 2,19$)$ dengan nilai $(p=0,031)$. Sehingga dapat disimpulkan bahwa PMR dan GI dapat mengurangi kecemasan dan memperbaiki keadaan mood pada orang tua dan anakanak dengan kasus keganasan.

Penelitian lain dilakukan oleh (Gupta, Kumari, \& Kaur, 2016), bertujuan untuk menilai efektivitas tekhnik PMR pada manajemen gejala fisik pasien kanker yang menerima kemoterapi. Sampel terdiri dari 60 Subyek kanker yang menerima kemoterapi di rumah sakit yang dipilih dari Amritsar, Punjab. (30 di kelompok eksperimen dan 30 di kelompok kontrol). Pada hasil penelitian menunjukkan intensitas muntah dalam percobaan kelompok selama penilaian pra-intervensi, mayoritas $(86,7 \%)$ memiliki intensitas sedang. Muntah diikuti intensitas ringan $13,3 \%$ muntah dan pasca intervensi mayoritas $(70 \%)$ tidak diikuti oleh $26,7 \%$ memiliki intensitas muntah ringan dan 3,3\% sedang sedang muntah. Nilai antara pra-intervensi dan post intervention 4,862 yang ditemukan secara statistik sangat signifikan ( $\mathrm{p}<0,001)$. Di kelompok kontrol selama pra-intervensi penilaian, 
mayoritas $(83,3 \%)$ telah muntah sedang diikuti $10 \%$ memiliki intensitas ringan muntah diikuti dengan $6,7 \%$ memiliki intensitas muntah yang tinggi dan di pasca intervensi mayoritas (80\%) telah muntah sedang diikuti $13,3 \%$ memiliki intensitas muntah ringan dan $6,7 \%$ memiliki intensitas muntah yang tinggi. Nilai antara intervensi pra-intervensi dan pasca 1.0 yang ditemukan secara statistik tidak signifikan pada kelompok kontrol pada $p$ $<0,05$. Sehingga dapat disimpulkan bahwa teknik PMR sangat efektif dalam mengurangi gejala fisik pada pasien kanker yang mendapat kemoterapi.

Penelitian lain dilakukan oleh (Herizchi et al., 2012), bertujuan untuk mengetahui pengaruh latihan PMR terhadap kecemasan dan depresi pada pasien kanker yang menjalani kemoterapi. Sampel 60 pasien yang didiagnosis dengan kanker yang menjalani kemoterapi. Hasil penelitian menunjukkan sebagian besar peserta merasa puas dengan belajar dan mengalami teknik ini. Tidak ada perbedaan yang signifikan antara sisik dalam kasus dan kelompok kontrol setelah satu bulan $(p>0,05)$. Namun setelah 3 bulan, kecemasan dan depresi jauh meningkat pada pasien yang menjalani latihan relaksasi otot progresif dengan nilai $(p<0,05)$. Sehingga dapat disimpulkan bahwa latihan PMR dapat menurunkan kecemasan dan depresi pada penderita kanker.

Penelitian lain dilakukan oleh (Syarif \& Putra, 2014), bertujuan untuk mengidentifikasi pengaruh PMR terhadap penurunan kecemasan pada pasien kanker yang menjalani kemoterapi di BLU RSUDZA. Sampel yang diteliti sebanyak 30 orang responden yang menjalani kemoterapi di ruang Mamplam III BLU RSUDZA. Hasil penelitian menunjukkan bahwa ada perbedaan yang signifikan skor kecemasan pada pengukuran kedua antara kelompok intervensi dan control dengan nilai $(p=0,003)$.

Hasil penelitian ini juga sejalan dengan penelitian yang dilakukan oleh (Haryati \& Sitorus 2015), bertujuan untuk mengetahui pengaruh latihan relaksasi otot progresif terhadap status fungsional dalam konteks asuhan keperawatan untuk pasien kanker dengan kemoterapi. Sampel yang diteliti sebanyak 48 orang yang terdiagnosa kanker. Hasil penelitian menunjukkan bahwa ada peningkatan signifikan dari rata-rata status fungsional setelah pelatihan PMR pada kelompok intervensi $(p=0,000)$. Artinya, pelatihan PMR berpengaruh pada peningkatan tingkat status fungsional pasien kanker dengan kemoterapi. Dianjurkan untuk menerapkan pelatihan PMR sebagai intervensi keperawatan kepada pasien kanker dengan kemoterapi dan menyarankan untuk melakukan penelitian lebih lanjut dengan menggunakan lebih banyak sampel.

Penelitian lain dilakukan oleh (Song, Xu, Zhang, Ma, \& Zhao, 2013), bertujuan untuk menilai apakah PMR dapat mengurangi kecemasan dan reaksi yang merugikan lainnya selama kemoterapi pada pasien dengan kanker payudara atau tidak. Sampel yang diteliti sebanyak 100 pasien kanker payudara yang dibagi menjadi 2 kelompok. Hasil penelitian menunjukkan skor dasar ratarata serupa antara kelompok kontrol dan kelompok eksperimen sebelum kemoterapi dimulai. Setelah kemoterapi, semua tindakan pada kelompok kontrol meningkat secara signifikan dari awal sementara semua ukuran pada kelompok eksperimen serupa dengan garis dasar. Setelah kemoterapi, skor kesehatan mental 
dan fisik pada kelompok eksperimen jauh lebih rendah daripada kelompok kontrol ( $p<0,05)$. Sehingga dapat disimpulkan bahwa latihan relaksasi selama kemoterapi dapat mengurangi kecemasan dan efek samping lain pada pasien kanker payudara pasca operasi.

\section{KESIMPULAN DAN SARAN}

Setelah intervensi pemberian latihan progressive muscle relaxation, terjadi penurunan kecemasan pada pasien kanker yang menjalani kemoterapi. Hal ini terlihat dari adanya pengaruh pada kondisi fisik pasien yaitu rasa lelah post treatment intervensi progressive muscle relaxation.

Institusi pendidikan diharapkan dapat menjadikan PMR sebagai bahan pembelajaran terapi komplementer pada mahasiswa sebelum praktik profesi untuk pasien di rumah sakit. Selain itu, rumah sakit diharapkan mampu memberi dan memfasilitasi pelatihan PMR pada perawat terutama di ruang perawatan yang memiliki pasien dengan pengobatan kemoterapi untuk meningkatkan derajat kesehatan yang lebih baik pada pasien di rumah sakit. Literatur review ini memerlukan penelitian yang lebih lanjut dengan intervensi yang lebih lama dan jumlah sampel yang lebih banyak.

\section{DAFTAR RUJUKAN}

Corwin, E. J. (2008). Homeostasis and the Stress Respons. in Handbook of Pathophysiology (3rd ed). philadelphia: Lippincott Williams \& Wilkins.

Gupta, B., Kumari, M., \& Kaur, T. (2016). Effectiveness of progressive muscle relaxation technique on physical symptoms among patients receiving chemotherapy, (1), 3340.
Haryati, \& Sitorus, R. (2015). Pengaruh Latihan Progressive Muscle Relaxation Terhadap Status Fungsional Dalam Konteks Asuhan Keperawatan Pasien Kanker dengan Kemoterapi di RS Dr.Wahidin Sudirohusodo Makassar. Medula, 2(2), 167-177.

Herizchi, S., Asvadi, I., Piri, I., \& Golchin, M. (2012). Efficacy of Progressive Muscle Relaxation Training on Anxiety, Depression and Quality of Life in Cancer Patients Undergoing Chemotherapy at Tabriz Hematology and Oncology Research Center , Iran in 2010, 3(1), 9-13.

Lee, E., Bhattacharya, J., Sohn, C., \& Verres, R. (2012). Monochord sounds and progressive muscle relaxation reduce anxiety and improve relaxation during chemotherapy: A pilot EEG study ¿. Complementary Therapies in Medicine, 20(6), 409-416. https://doi.org/10.1016/j.ctim.2012 .07 .002

Montaño, D. E., \& Kasprzyk, D. (2008). Health behaviour and health education: theory, research, and practice. Theory of reasoned action, theory of planned behavior, and the integrated behavioral model. Health behavior: Theory, research and practice. https://doi.org/http://hdl.handle.net /2027/spo.10381607.0007.102

Pusdatin. (2016). InfoDatin Bulan Peduli Kanker Payudara. Kementrian Kesehatan.

Rekam Medik. (2018). Data Pasien Kanker Payudara yang Menjalani Kemoterapi. Makassar. 
Shahriari, M., Dehghan, M., Pahlavanzadeh, S., \& Hazini, A. (2017). Effects of progressive muscle relaxation, guided imagery and deep diaphragmatic breathing on quality of life in elderly with breast or prostate cancer. Journal of Education and Health Promotion, 1-6. https://doi.org/10.4103/jehp.jehp

Song, Q., Xu, R., Zhang, Q., Ma, M., \& Zhao, X. (2013). Relaxation training during chemotherapy for breast cancer improves mental health and lessens adverse events, 6(10), 979-984.

Syarif, H., \& Putra, A. (2014). Pengaruh Progressive Muscle Relaxation Terhadap Penurunan Kecemasan Pada Pasien Kanker Yang Menjalani Kemoterapi; A Randomized Clinical Trial. Idea Nursing Journal, V(3), 1-8.

Tsitsi, T., Charalambous, A., Papastavrou, E., \& Raftopoulos, V. (2017). Effectiveness of a relaxation intervention (progressive muscle relaxation and guided imagery techniques) to reduce anxiety and improve mood of parents of hospitalized children with malignancies: A randomized controlled trial in Republic of Cyprus and Gre. European Journal of Oncology Nursing, 26, 9-18. https://doi.org/10.1016/j.ejon.2016 .10 .007

Zhou, K., Li, X., Li, J., Liu, M., Dang, S., Wang, D., \& Xia, X. (2014). A clinical randomized controlled trial of music therapy and progressive muscle relaxation training in female breast cancer patients after radical mastectomy: Results on depression, anxiety and length of hospital stay. European Journal of Oncology Nursing, 1-6. https://doi.org/10.1016/j.ejon.2014 .07 .010 